\title{
El ars poetria en el cine: repercusiones de la teoría de la amplificación de Geoffrey of Vinsauf en la narrativa audiovisual
}

\section{The ars poetria in Films: Repercussions of Geoffrey of Vinsauf's Theory of Amplification in Audiovisual Narrative}

\author{
Juan Manuel Arriaga Benítez \\ Universidad Nacional Autónoma de México \\ hector_aquiles_apolo@hotmail.com
}

\begin{abstract}
RESUMEN
En el presente trabajo se analiza la participación de las figuras o técnicas de amplificación descritas por el poeta normando del siglo xiii Geoffrey of Vinsauf en las dimensiones retóricas clásicas conocidas como dispositio (estructura) y elocutio (estilo), con el fin de ejemplificar cómo en el cine se puede presenciar su uso en forma de diseño de imagen a través de la fotografía, la composición visual y el montaje escénico. A partir de este estudio es posible advertir también cómo los guionistas y directores han sido capaces de ofrecer significado moral o emocional al espectador.
\end{abstract}

Palabras Clave: retórica, narrativa, amplificación, tradición clásica, cine

\begin{abstract}
In this work it has been analized the participation of figures or techniques of amplification described by Geoffrey of Vinsauf, norman poet from 13th century, into the classical rhetoric dimensions known as dispositio (structure) and elocutio (style), so that I can exemplify how in film industry it can be witnessed its use in form of image design through cinematography, visual composition and scenic assembly. From this study, it is also possible to notice how screenwriters and directors have been able to offer moral or emotional meaning to the viewer.
\end{abstract}

KEYWORDS: rhetoric, narrative, amplification, classical tradition, films

FECHA DE RECEPCIÓN: 28/10/2019

FECHA DE ACEPTACIÓN: 14/02/2020 


\section{INTRODUCCIÓN}

$\mathrm{L}$ a manipulación de un texto desde el aspecto de su narrativa supuso para Geoffrey of Vinsauf (aunque, en general, también para los demás escritores de artes poetriae) una oportunidad de readaptar la poética clásica a paradigmas más doctrinales y de mayor profundidad gramatical. Esto lo condujo a establecer modelos específicos que tenían un fuerte contenido preceptivo, entre los que destaca, dentro de las dimensiones de estructura y estilo, la amplificación, doctrina que queda comprendida en ocho figuras de lenguaje bien delimitadas en su Poetria Nova y cuyo denominador común es detener o suspender la marcha de la trama en un momento que le permita a un autor extenderlo a voluntad y enfatizar en sus contenidos temáticos. ${ }^{1}$

116 La amplificación, por ende, se constituyó como una teoría lingüística en la que se discutieron las diversas técnicas con las que un escritor podría extender a voluntad cualquier escena de su texto, con el fin de darle así relevancia o permitirle transmitir una intención didáctica (Baltzell, "Rhetorical", 33) dentro de la estructura de toda una narrativa, por lo que, como doctrina, las técnicas para amplificar son una de las grandes aportaciones de las artes poetriae a la narrativa preceptiva (Murphy, Rhetoric, 176) y, a mi juicio, a la órbita fílmica en cuanto que el uso gramatical y sintáctico de la imagen da soporte a la narrativa audiovisual.

En términos de amplificación, la Poetria Nova del poeta Geoffrey of Vinsauf presenta un paradigma de ocho estrategias destinadas a que la materia narrativa no trabajada adquiera, una vez que pasa por el proceso de invención recomendada por el mismo poeta, la elocución adecuada que le garantice la belleza e importancia pretendida. Como se puede inferir, es esta una teoría a la que se adscribe una reinvención de las técnicas retóricas antiguas, pues delimita preceptivamente los campos que permiten extensión narrativa sin mermar el proceso creativo del autor ni su injerencia en la estructura.

Las técnicas de amplificación no sólo han quedado adscritas a los fenómenos lingüísticos, sino que también han arrojado excelentes resultados en géneros audiovisuales, como el cine y la televisión, pues plantean nuevas vías de desarrollo, según pretendo demostrar, y las secuencias visuales las han

\footnotetext{
${ }^{1}$ Si bien esta definición es propia, está basada en dos nociones, una que analiza el sustrato de tradición clásica y las variantes de su expresión (Beltzell, "Rhetorical”) y la otra que considera el aspecto cinematográfico (en específico sobre el estilo del director Martn Scorsese) en cuanto a la imagen y la anticipación de los contenidos temáticos de una trama cinematográfica (Castellitto, “Imagism”, 23 ss.).
} 
recibido aderezadas con los tipos de planos y tomas que facilitan a una cámara la narración de una historia.

En el presente artículo analizaré, con un método descriptivo-ejemplificativo, cómo las propuestas fílmicas modernas han recibido las técnicas de amplificación medieval como una doctrina tácita cuya principal repercusión es la de embellecer una historia dotándola de efectos muy característicos que permiten una mejor lectura de las intenciones de un guionista o un director (las cuales pueden ir desde resaltar a un personaje, enfatizar una situación o fundamentar significados morales); sobre este razonamiento, es necesario afirmar que el uso de estas herramientas de lenguaje en el cine no sólo proporciona a los cineastas opciones que plantean experiencias visualmente más atractivas o mejor enfatizadas desde la perspectiva de un espectador, sino que también facilita la diversificación de las propuestas narrativas y, en consecuencia, la variación de contenidos temáticos que pueden mostrarse incluso para tramas de evidente semejanza, pues permite que la adaptación audiovisual desde cualquier material precedente (un libro, un cómic, un poema u otra película) manifieste un proceso creativo propio y refiera originalidad en la manipulación de su contenido.

Cabe destacar dos cuestiones relevantes. 1. Las traducciones que tomo de algunos versos de la Poetria Nova de Vinsauf pertenecen a la edición publicada en el año 2000 por la doctora Carolina Ponce Hernández, por lo que reflejan una labor institucional que funge como canon semántico en español. 2. Las películas con las que ejemplifico y explico las diversas técnicas de amplificación tienen un estatus clásico y fueron diseñadas por directores con alto prestigio en la industria hollywoodense, por lo que garantizan la recepción de las teorías clásicas de los escritores de guion ${ }^{2}$ que más han influido en la industria fílmica; aun cuando no haya una teoría sobre la influencia de las poetriae medievales en los manuales de guion o en los procesos creativos de los cineastas, quienes parecen obviar la trayectoria histórica de las teorías, me es posible rastrear aspectos de interés para este tópico a través de las referencias que ofrecen académicos como Pedro L. Cano o Andrés Alés Sancristóbal, los cuales han especulado la influencia de elementos clásicos (sobre todo de raigambre aristotélica y horaciana) en el ámbito de la construcción narrativa fílmica.

\footnotetext{
${ }^{2}$ En la bibliografía se consignan las obras de Syd Field, Robert McKee y John Truby, a quienes considero los representantes más destacados que evidencian esta recepción; en este sentido, no menos importante, pero encaminado hacia el ámbito de la interpretación retórica y desde una perspectiva más académica, resulta David Bordwell.
} 


\section{TÉCNICAS DE AMPLIFICACIÓN COMO HERRAMIENTAS DEL DISCURSO CINEMATOGRÁFICO}

La amplificación es una doctrina que Vinsauf hace participar tanto de la dispositio como de la elocutio. Puesto que toman parte de ambos campos de la retórica clásica, las técnicas de amplificación, dentro de la Poetria Nova, están a la mitad de ambas disciplinas y constituyen, junto a la teoría de la abreviación y la de los adornos estilísticos (también explicadas por Vinsauf) elementos que dotan de estructura y ornamento a una trama.

La diversidad de las técnicas de amplificación no se debe al número total recurrente en las artes poetriae, sino más bien a la amplia gama de oportunidades que ofrece su uso. Si bien la cantidad de figuras para amplificar pare118 ce reducida, la participación en dos dimensiones del proceso retórico y su adaptabilidad a contenidos temáticos diversos estimulan una más compleja inserción en las narrativas de cualquier género literario, incluido el cinematográfico.

El siguiente esquema reproduce más claramente esta noción, pues permite localizar la teoría de la amplificación dentro del marco metodológico de la retórica: ${ }^{3}$

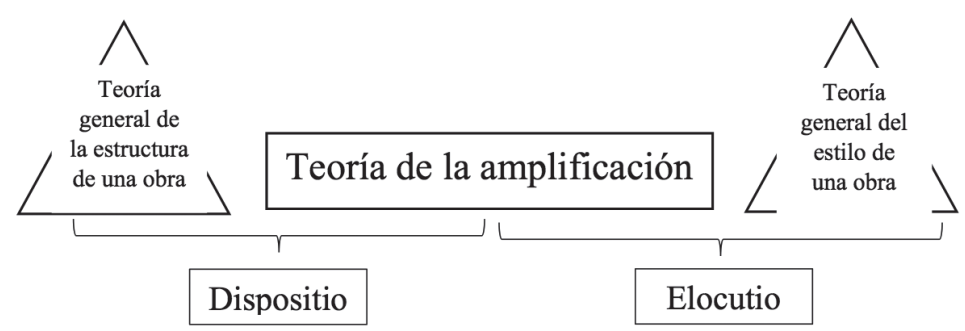

Fig. 1. Esquema de la teoría de la amplificación

Como se observa, dispositio (estructura argumental) y elocutio (estilo y ornamentación) dimensionan el campo de la amplificación como una teoría

\footnotetext{
${ }^{3}$ El esquema con que Tomás Albaladejo relaciona las directrices de texto y hecho retórico puede ilustrar también mis afirmaciones, pues reproducen los aspectos metodológico y estructural del discurso (Retórica, 44). En este sentido, el producto del hecho retórico aplicado al cine es una película, concebida como una construcción con una intención comunicativa, mientras que las figuras de amplificación mantienen para el producto fílmico un balance entre la dupla dispositio-elocutio y la inventio.
} 
completa que supone, para un contexto medieval, un avance con respecto a los modelos clásicos.

Desde su dimensión estructural, la amplificación transmite soporte rítmico a una narrativa, sobre todo a una trama cinematográfica, pues marca elementos o situaciones de importancia dentro de toda ésta y logra destacarlos para el público, de modo que el espectador recibe la película con una carga de escenas o secuencias capaces de atraer su atención hacia momentos de importancia narrativa.

Desde su dimensión ornamental, las técnicas de amplificación proporcionan efectos en la narración y fílmicamente funcionan como detonantes emocionales que se perciben como atractivos, tanto a nivel de imagen como a nivel sintáctico, es decir, mediante el uso de aquéllas para el montaje de escenas y secuencias, pero también para la construcción dialógica en la que se implica el uso de los personajes para referirlas oralmente.

Con el fin de ejemplificar algunos de esos usos, tanto en el plano estructural como en el estilístico, considérense las siguientes escenas que se sirven de esas técnicas de amplificación:
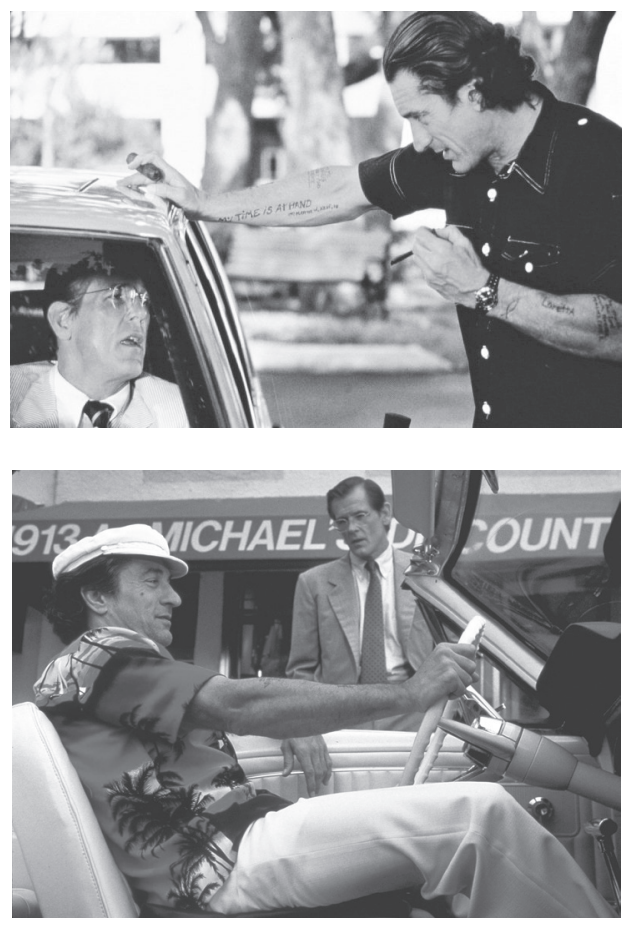

Figs. 2 y 3. Fotogramas de Cape fear, Martin Scorsese, 1991 
Las imágenes reproducen una collatio (comparación), técnica de amplificación estructural usada en esta película con el fin de mostrar tanto las semejanzas como las diferencias que existen entre los personajes protagonista y antagonista con la intención de comunicar la confrontación que entre ambos se gesta. Sendas imágenes participan de la dimensión estructural de la amplificación, pues establecen momentos en los que el paralelismo entre ambas escenas destaca las características de los personajes y les atribuye la prominencia necesaria mediante un ritmo narrativo balanceado.

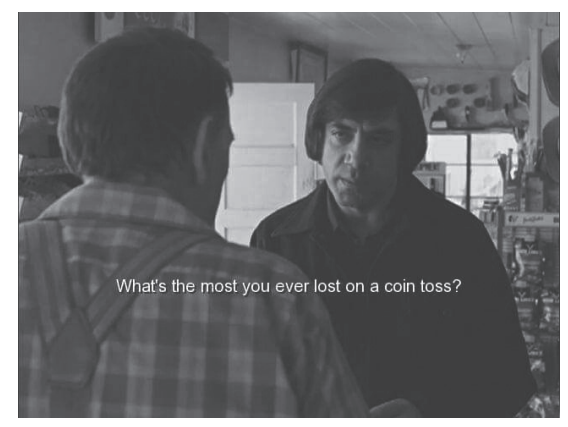

Fig. 4. Fotograma de No country for old men, Joel e Ethan Coen, 2007

En la imagen se muestra una escena en la que el personaje Anton Chigurh (Javier Bardem) manifiesta reiterativamente a su interlocutor su intención de echar a la suerte su vida, luego de lanzar una moneda. Esta escena reproduce una interpretatio (reasumir una expresión mediante reiteración). La escena mostrada participa de la dimensión ornamental, pues cimienta el carácter del personaje y establece un referente paradigmático que será imprescindible para entender otras escenas de la película en las que se implica este recurso narrativo.

El carácter tanto estructural como ornamental de la amplificación está explícitamente configurado por Vinsauf para expresar un significado particular, es decir, se adscriben como herramientas didácticas que manifiestan intenciones morales o emocionales. Los dos ejemplos presentados anteriormente tienen en común la intención de mostrar un significado cifrado mediante un subtexto con el que, sea a nivel de imagen, sea a nivel gramatical, el espectador obtiene una experiencia visual significativa, la cual a la vez detona emociones a través del montaje específicamente diseñado ad hoc.

Este diseño es análogo al pretendido por las poetriae medievales, según refiere Baltzell del siguiente modo: "All eight devices of amplification, then, were means of molding narrative raw material into a structure calculated to make a didactic sententia ultimately accessible, while at the same time 
masking it sufficiently to insure that the work of interpretation would be interesting and pleasant and require a measure of effort and skill" ("Rhetorical", 35); sin embargo, a mi parecer, en la Poetria Nova de Vinsauf adquieren una particular condición meta-narrativa, pues también participan de sus dispositio y elocutio dentro del poema no sólo de forma preceptiva, sino también poética, como herramientas de su discurso. ${ }^{4}$

${ }^{4}$ La Poetria Nova está estructurada con fundamento en la retórica clásica, según lo esquematiza Carolina Ponce en su traducción (La poética nueva, XVIII y XXIV), de modo que a la vez reproduce la estructura de un discurso y la metodología retórica según los siguientes esquemas:

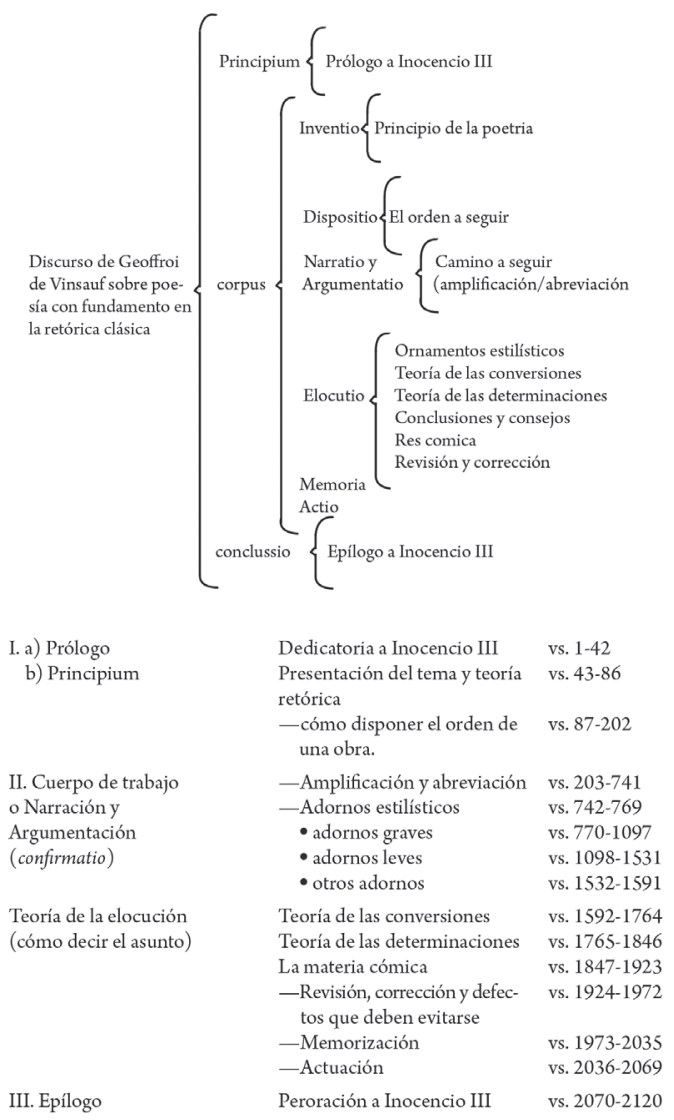

Figs. 5 y 6. Esquemas de la Poetria Nova (Vinsauf, La poética nueva, 12 y 9) 


\section{FIGURAS DE AMPLIFICACIÓN: APROXIMACIÓN TEÓRICA}

La teoría de la amplificación de Vinsauf abarca desde el verso 220 hasta el 694 de la Poetria Nova, luego de una breve introducción en la que adscribe la siguiente afirmación a la idea de la diversificación que adquiere el proceso de amplificar o abreviar: "variada marcha al principio ha dado el arte prescrito". 5 Esa "variada marcha" puede entenderse como un ritmo constante en el que las figuras de amplificación juegan un papel importante, ya que permiten resaltar o enfatizar, como se ha dicho anteriormente, aspectos a los que el autor le concede relevancia o que pretende que el espectador interprete detenidamente.

Las ocho técnicas que contiene la teoría de la amplificación del poeta normando se describen a continuación con sus propias palabras:

- Interpretatio (reasumir la expresión): consiste en "repetir una cosa en varias cláusulas", 6 de modo que una misma idea pueda revestirse de varias formas de elocución con el fin de marcar un énfasis que, no obstante, no resulte aburrido, torpe o repetitivo. Se trata de una figura muy cercana a la paráfrasis, aunque con expresiones breves que parecieran ráfagas de ideas más que grandes períodos discursivos o narrativos.

- Perifrasis (circunlocución): ocurre cuando una expresión "desarrolla un discurso suplente suyo en una larga y dilatada serie de palabras"; ${ }^{7}$ es decir, el autor da tratamiento a un asunto mediante expresiones extensas y detalladas, de modo que una situación narrativa, que pudiera resolverse en pocas palabras, se extienda mediante redundancias y capte detalles que embellezcan el contenido.

- Collatio (comparación): es una técnica sencilla que refiere una relación, como la oppositio, pero de forma que las características de una situación narrativa produzcan satisfacción y encanto, "donde las cosas unidas así se ligan y se tocan, como si no fueran contiguas, sino continuas"; ${ }^{8}$ en otras palabras, la comparación embellece una expresión en la medida en la que la narrativa

${ }^{5} C f$. v. 203: principio varium dedit ars praescripta tenorem. Ésta y las subsiguientes traducciones están basadas en las de la edición de Carolina Ponce, aunque no de manera literal, pues consideré que para ciertos vocablos existe una interpretación más adecuada.

${ }^{6} \mathrm{Cf}$. vv. 223-224: repone / pluribus in clausis unum.

${ }^{7}$ Cf. vv. 227-228: fit sermo vicarius eius / in serie vocum longa serieque morosa.

${ }^{8}$ Cf. vv. 259-261: res ubi junctae / sic coeunt et sic se contingunt, quasi non sint / contiguae, sed continuae. 
se asemeje a la naturaleza y se apropie de aspectos que le dan fluidez a la elocución.

- Apostropha (apóstrofe, reclamo): se trata de una técnica de amplificación más referida a la expresión dialógica que a la visual, pues Vinsauf la establece casi exclusivamente como dependiente de formas de elocución en las que los personajes imprecan o someten a reclamos con una intención didáctica o preceptiva. Cabe mencionar que esta figura es de la que más ejemplos ofrece el poeta normando, pues muy variadas son las oportunidades que una narrativa podría ofrecer para que un reclamo pudiera introducirse; sin embargo, esta estrategia de amplificación ofrece también la posibilidad de detonar emociones que doten de significado moral a la estructura narrativa.

- Prosopopeia (personificación): consiste en convertir casi cualquier objeto o idea inanimada en un personaje, de modo que se le dé "el privilegio de hablar y que la licencia le permita el lenguaje". Se trata de una figura interesante, porque ofrece la posibilidad de introducir elementos narrativos originales a la trama y otorgarle características que pudieran dar soporte a la situación desde una perspectiva didáctica y emocional.

- Digressio (digresión): literalmente significa "desviación” y sucede cuando el autor cambia el tema del que está tratando o se aparta del asunto principal, con el fin de permitir un descanso al espectador o mostrar ciertos elementos narrativos que, aunque parecieran innecesarios, contienen una dosis de encanto o enseñanza. Vinsauf afirma que, si bien alejarse resulta conveniente en algunos momentos de la trama, no conviene alejarse mucho para no perder el paso sobre el asunto principal que acontece.

- Descriptio (descripción): bastante recurrida por ser necesaria visualmente, esta técnica de amplificación ofrece el mayor atractivo estructural de las ocho, pues permite concebir en forma de imágenes los detalles que recrean personajes, lugares y situaciones dentro de una narración; aunque posee muchas variantes, Vinsauf afirma que esta figura puede resultar extensa, por lo que aconseja que "en forma par sea preciosa y espaciosa". ${ }^{10}$

- Oppositio (oposición, confrontación): muy como la collatio, la oposición resulta de la relación bivalente entre dos aspectos que se introducen en una narrativa; sin embargo, ésta es producto de una confrontación de ideas o conceptos, de modo que una expresión "expone el asunto propuesto y la otra suprime el opuesto" ${ }^{11}$ La oposición ofrece la posibilidad de discutir opciones

${ }^{9}$ Cf. vv. 462-463: cui nulla potentia fandi / da licite fari donetque licentia linguam.

${ }^{10}$ Cf. v. 561: pari forma speciosa sit et spatiosa.

${ }^{11} \mathrm{Cf}$. vv. 675-676: altera propositam rem ponit et altera tollit / oppositam. 
o de establecer argumentación dentro de perspectivas antitéticas entre personajes, por lo que puede conducir la trama hacia conflictos diseñados.

La película Casablanca (Michael Curtiz, 1942) integra todas estas figuras de manera balanceada y formidable. Por ser un producto cinematográfico que "muestra la técnica más clásica de la retórica" (Cano, De Aristóteles, 132), es verosímil suponer que la amplificación haya sido una de las directrices mejor cimentadas de esa producción, pues su inclusión dentro de la película integra, además, un lenguaje profundamente connotativo, muchas veces metafórico, que permite inferir un guion elaborado con un cuidadoso manejo de su narrativa.

Prueba de ello es su oppositio, que ocurre en un momento de la trama en el que nazis e inmigrantes europeos se confrontan mediante sus himnos en el café de Rick (Humprey Bogart) durante una de las primeras secuencias de la película, siendo un elemento estructural que connota el contexto bélico de la trama y un elemento ornamental al detonar emociones vívidas de efusivo patriotismo que permean el subtexto narrativo (los aliados superan a las potencias del eje) y anticipan contenidos temáticos (la Alemania nazi es vencida).

\section{CONCLUSIONES}

Dentro del espectro cinematográfico, las películas ofrecen una gama más amplia de oportunidades con las que utilizar estas técnicas de amplificación, pues el recurso audiovisual, análogo al del teatro, diversifica el soporte retórico que aquellas arrastran desde la directriz de la tradición clásica.

La teoría que subyace a esta afirmación fue enunciada por Laurence Behrens, cuya idea central permite comprender al cine como una construcción tanto retórica como dramática ("The Argument", 3), es decir, participa tanto del discurso como de la narrativa, por lo que es posible inferir que los elementos estructurales y elocutivos recogidos por las artes poetriae son también aportaciones a la teoría de construcción tanto retórica como poética y han sido recibidos, aun cuando no se mencionen en los manuales de guion más representativos, ${ }^{12}$ por la tradición cinematográfica. ${ }^{13}$

12 Pedro L. Cano teoriza que existe una communis doctrina entre quienes integran la clase de guionistas hollywoodenses, especialmente en Syd Field (El manual del guionista, 17), pues manejan un lenguaje audiovisual análogo al que presenta la Poética aristotélica, fuente de la narrativa y la composición literaria.

13 Los más representativos, a mi juicio, son El guión de Robert Mckee, The Anatomy of Story de John Truby y El manual del guionista de Syd Field, no sólo porque los tres refieren introductoriamente a Aristóteles, sino porque en ellos me ha sido posible vislumbrar cómo la 
Si bien Aristóteles es el autor más referenciado como modelo de guion gracias a su Poética, lo cierto es que el filósofo griego fundamenta una teoría de recepción clásica en el cine sólo en el terreno de la poética, mientras que un análisis de la retórica heredada por Vinsauf en su Poetria Nova sí es capaz de soportar los vínculos existentes entre las metodología tanto para discurso como para narrativa.

El uso de la amplificación (de la misma medida que el de la abreviación) ofrecen grandes ventajas al guionista y al director para lograr una mejor calidad en la fotografía; ésta, pues, adquiere una propiedad altamente connotativa de acuerdo con la intención didáctica que se pretenda, tal como a continuación se demuestran.

Los tres ejemplos siguientes pertenecen a tres secuencias distintas de una misma película, The Godfather, presentando respectivamente una descriptio, una collatio y una apostropha que poseen significados precisos desde un punto de vista moral, pues resaltan las tres características etiológicas de tres distintos personajes congruentes a su vez con sendas dimensiones de estructura y ornamento, según el diseño de la trama.

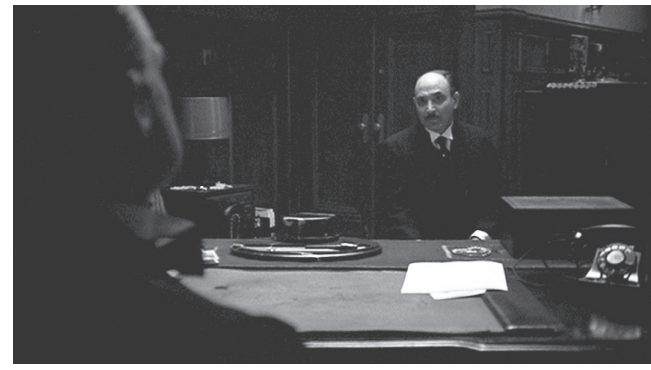

Fig. 7. Fotograma de The Godfather, Francis Ford Coppola, 1972

Esta primera imagen pertenece a la escena inicial de la película; su fotografía presenta una toma cerrada al rostro del personaje que, a medida que ocurre su narración, se abre para revelarlo por encima del hombro de Don Vito Corleone (Marlon Brando) mediante claras alusiones a la ambigüedad moral gracias a las sombras que se figuran en el rostro de aquél; todo esto participa de la elocutio, mientras que para la dispositio el diseño de la escena anticipa la trama mediante un ejemplo y revela las características del personaje central.

tradición de las poetriae medievales ha tenido una vigencia implícita, sobre todo en el aspecto preceptivo que caracteriza estas obras. 


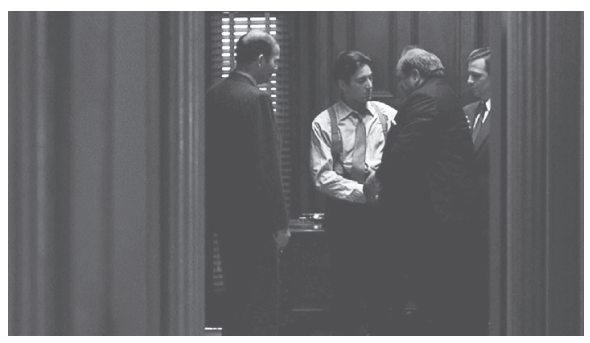

Fig. 8. Fotograma de The Godfather, Francis Ford Coppola, 1972

La segunda imagen pertenece a la secuencia final de la película y funciona estructuralmente como una reminiscencia del padre de Michael Corleone 126 (Al Pacino), quien en la imagen se le reconoce como el nuevo Padrino de la mafia; ornamentalmente, sin embargo, esta collatio influye en el espectador de forma profundamente emocional, pues le refiere el fin del arco argumental de Michael, a pesar de su negativa a heredar el negocio familiar; de hecho, el montaje de la escena se ofrece desde la perspectiva de su esposa, quien lo ve desde lejos y en una toma muy abierta, significando el comienzo de una nueva etapa en la vida personal de Michael y un nuevo rumbo para la mafia 5 italiana en Norteamérica.

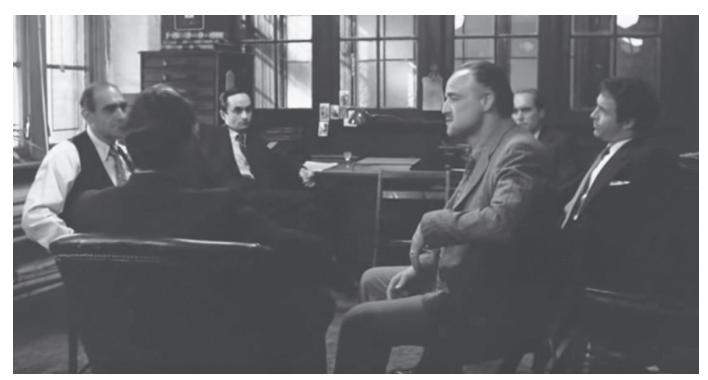

Fig. 9. Fotograma de The Godfather, Francis Ford Coppola, 1972

Por su parte, la tercera imagen pertenece a la icónica escena en la que Vito Corleone rechaza la oferta de Virgil Sollozzo (Al Lettieri) sobre el negocio de los narcóticos; la escena presenta un breve discurso de Vito en el que se ejemplifica un modo sutil de negociar, por lo que el recurso de la apóstrofe queda no sólo referido al diálogo de los personajes, sino al contexto mismo de la trama, pues la escena es una coyuntura estructural que desencadena ciertas vicisitudes para el personaje de Vito y sus hijos; la composición de la escena muestra, de hecho, del lado izquierdo los personajes que se convertirán en 
traidores de la familia Corleone: el ya mencionado Virgil, Salvatore Tessio (Abe Vigoda) y Fredo Corleone (John Cazale); mientras tanto, del lado derecho aparecen los grandes aliados del capo: Santino Corleone (James Caan) y Tom Hagen (Robert Duvall).

Esta muestra de evidencia me permite inferir que, en efecto, la industria cinematográfica, proveniente de los modelos preceptivos de las poetriae, que a su vez recogen la tradición retórica y poética de la Antigüedad, ha incorporado, al menos tácitamente y por medio de procesos de desenvolvimiento histórico que no se analizan en el presente trabajo, las distintas técnicas sintácticas y gramaticales que permitían dar estructura, ornamento y significado a las creaciones literarias y las composiciones poéticas, de modo que la imagen en movimiento y los recursos técnicos han podido incrementar las posibilidades de lograr una mejor disposición del material que fundamenta la trama y una mejor elocución del sustento poético que genera las expresiones o sententiae, dotando así de significado al contenido temático (Baltzell, "Rhetorical”, 36).

Por lo tanto, la industria cinematográfica parece haber recibido indirectamente la teoría de la amplificación medieval, puesto que los directores y guionistas hacen uso de sus técnicas a través del diseño de escenas y la composición visual. Por lo que se ha querido resaltar en este trabajo, es posible también comprender que el cine y la narrativa fílmica presentan amplificación de los contenidos y las estructuras de una trama con el fin de transmitir momentos de significado moral y emocional, intención análoga a la que Geofrrey of Vinsauf fundamenta en su Poetria Nova.

\section{BIBLIOGRAFÍA}

Albaladejo, Tomás, Retórica, Madrid: Síntesis, 1991.

Baltzell, Jane, "Rhetorical 'Amplification' and 'Abreviation' and the Structure of the Medieval Narrative", Pacific Coast Philology, 2, 1967, 32-39.

Behrens, Laurence, "The Argument in Film: Applying Rhetorical Theory to Film Criticism”, Journal of the University of Film Association, 31:3, 1979, 3-11.

Bordwell, DAvid, Making Meaning. Inference and Rhetoric in the Interpretation of Cinema, Cambridge, Massachusetts: Harvard University Press, 1989.

CAno, Pedro L., De Aristóteles a Woody Allen: poética y retórica para cine y televisión. Barcelona: Gedisa, 1999.

Castellitto, George, Imagism and Martin Scorsese: Images Suspended and Extended. Literature Film Quarterly, 26:1, 1998, 23-29.

Coen, E., J. Coen y S. Rudin (productores) y E. Coen y J. Coen (directores), No 
Country for Old Men [cinta cinematográfica], Los Angeles: Miramax Films, Paramount Vantage, Scott Rudin Productions, Mike Zoss Productions, 2007.

De Fina, B. (productor) y M. SconSESE (director), Cape Fear [cinta cinematográfica], Los Angeles: Amblin Entertainment, TriBeCa Productions, 1991.

FIeld, Syd, El manual del guionista, trad. de M. Heras, Madrid: Plot, 1996.

Mckee, Robert, El guión. Sustancia, estructura, estilo y principios de la escritura de guiones, trad. de J. Lockhart, Barcelona: Alba, 1997.

Murphy, James J., Rhetoric in the Middle Ages. A History of the Rhetorical History from Saint Augustine to the Renaissance, Arizona: Arizona Center of Medieval and Renaissance Studies, 2001.

Rudy, A. (productor) y F. Ford Coppola (director), The Godfather [cinta cinematográfica], Los Angeles: Paramount Pictures, Alfran Productions, 1972.

SANCRISTÓBAL, ANDrÉs A., "Las nuevas poéticas: de Aristóteles a Robert Mckee", CAUCE, Revista Internacional de Filología y su Didáctica, 31, 2007, 7-39.

Truby, John, The Anatomy of Story: 22 Steps to Becoming a Master Storyteller, New York: Faber and Faber, 2007.

Vinsauf, G. D., La poética nueva, trad. de C. Ponce Hernández, México: Universidad Nacional Autónoma de México, 2000.

Vinsauf, G. D., Poetria nova, trad. de A. M. Calvo Revilla, Madrid: Arco/Libros, 2009. 